\title{
Obsessive compulsive disorder in a woman with left basal ganglia infarct: A case report
}

\author{
Faustino Lopez-Rodriguez, Ibrahim Gunay and Nancy Glaser \\ Department of Psychiatry, UCLA School of Medicine, NPI\&H, 740 Westwood \\ Plaza, Los Angeles, CA 90024, USA \\ Correspondence to: Faustino Lopez-Rodriguez at above address
}

\begin{abstract}
This report presents a syndrome resembling obsessive convulsive disorder (OCD) secondary to a stroke in the left basal ganglia. The patient's syndrome is virtually identical to those that have been described in bilateral damage of the basal ganglia. However, the stroke described in this case report is located unilaterally in the left basal ganglia. In addition, experience in treating a patient with OCD induced by structural damage of basal ganglia is presented.
\end{abstract}

Keywords: Obsessive compulsive disorder - Stroke

\section{INTRODUCTION}

In recent years numerous studies have suggested that functional abnormalities of the basal ganglia are involved in the pathogenesis of OCD (for review, see Insel, 1992). In addition, there are a number of cases in which basal ganglia structural damage has been found in patients with obsessive compulsive (OC) symptoms (Croisile et al., 1989; Laplane et al., 1989; Maraganore et al., 1991; Weilburg et al., 1989), accompanied at times by a frontal lobe syndrome (Croisile et al., 1989; Laplane et al., 1989).

This report presents a syndrome resembling OCD secondary to a stroke. The patient's syndrome is virtually identical to those that have been described in bilateral damage of the basal ganglia (Laplane et al., 1989). However, the stroke described in this case report is located unilaterally in the left basal ganglia. In addition, experience in treating a patient with OCD induced by structural damage of basal ganglia is presented.

\section{CASE REPORT}

Mrs $\mathrm{J}$ is a 73-year-old right handed white female who, at the time of presentation to a geriatric psychiatry ward, displayed a marked loss of drive, apathy, emotional blunting and indifference to social interaction without a dysphoric mood. Neurological examination was remarkable only for the presence of frontal release signs as well as difficulties with alternating motor sequences (fist-blade-palm). In addition, she had com- pulsions to clean her mouth with tissue paper or other items, depending upon availability, and compulsions to drink sips of water continuously throughout the day. With questioning, she revealed that these behaviours were done to clean her mouth of "phlegm" which, although not readily seen, she experienced as distressing and contaminating and needing to be neutralised. If the tissue papers were removed from her side, she would get anxious and try to obtain other materials with which she could continue cleaning her mouth. Her obsessions and compulsions were not ego-dystonic as she lacked the insight that her obsession was bizarre and that her behaviour was ritualistic and abnormal. She did not try to resist these behaviours which occupied most of her time. Due to her apathy, she did not engage in a variety of activities, including the routine activities of daily living.

The past psychiatric history revealed a remote history of two post-partum depressive episodes, at least one of which was successfully treated with ECT. The patient did well until two years prior to admission, at which point she had a stroke which is not clearly defined symptomatically by the patient or her family other than as "equilibrium problems", mainly seen as an unsteady gait. A CT scan performed at that time showed a lacunar infarct in the left basal ganglia. Six months later, the patient began exhibiting the compulsive rituals described above and she became depressed. The depression failed to respond to treatment with nortriptyline and paroxetine. Two months prior to the 
current hospitalisation, the patient received 10 ECT treatments with resolution of the depression but she continued to manifest OC symptoms. After ECT, the patient was discharged on fluoxetine. At the time of readmission, the patient had been on fluoxetine $40 \mathrm{mg}$ for two months with no relapse of depression but without any amelioration of obsessions or compulsions.

MRI scan performed seven months after the stroke showed a lacunar infarct located in the lateral portion of the left putamen, extending to the external capsula. Additional findings in the MRI scan included generalised cortical atrophy and periventricular deep white matter ischemic disease not greater than expected for her age. A repeat MRI scan 17 months after the stroke did not show any significant change compared with the previous MRI. Conventional EEG studies depicted normal electrocerebral activities in awake and drowsy states. However, a functional quantitative EEG with brain mapping showed abnormal excess energy in slow wave bands in the left fronto-temporal areas, consistent with frontal dysfunction.

Neuropsychological testing revealed intact attention, word naming, basic language abilities and memory with impairment of fine motor coordination, figural and verbal fluency and executive functions. Other findings were behavioural disinhibition, poor initiation and difficulty sustaining effort.

Treatment goals during the hospital stay were to diminish the frequency of rituals, decrease apathy, and increase social interaction. Behaviour therapy was attempted and consultation sought from a cognitivebehavioural psychologist; however, the patient was a poor candidate due to her lack of insight and motivation. As the patient had not shown any response to two months of treatment with fluoxetine, risperidone $1 \mathrm{mg}$ every four hours was added without any effect after six days. Extrapyramidal symptoms did not appear after the neuroleptic was added. At this point, lithium carbonate $300 \mathrm{mg}$ twice daily was added and a dramatic decrease in the compulsive behaviour was seen four days later. However, there was no improvement in the frontal symptoms. Therefore, amantadine $100 \mathrm{mg}$ twice daily was added and an increase in initiative and decrease in apathy were noted. The patient was seen seven and 28 days post-hospitalisation by one of the team physicians and continued to maintain the improvement described above.

\section{DISCUSSION}

The fact that the patient did not have any psychiatric problems prior to the stroke indicates that the stroke may be responsible for the appearance of the OCD- like symptoms. The location of the stroke in the left basal ganglia is in agreement with current theories that posit basal ganglia dysfunction in the pathogenesis of OCD (for review, see Insel, 1992) and with reports of OCD appearance after bilateral structural damage of basal ganglia (Croisile et al., 1989; Laplane et al., 1989).

Another coincidence between the case reported in the present paper and classical OCD is the comorbidity of OCD with frontal syndromes. This comorbidity has been demonstrated by clinical criteria and neuropsychological testing (Head et al., 1989; Khanna, 1988; Laplane et al., 1989; Martinot et al., 1990) and confirmed by decreased power in the nondominant frontomedial and posterior temporal regions in computerised EEG (Gloor et al., 1977) and dysfunction of cortical metabolism (Laplane et al., 1989; Martinot et al., 1990; Rubin et al., 1992; Baxter et al., 1987, 1988; Nordhal et al., 1989; Swedo et al., 1989). The most plausible explanation for the appearance of frontal syndrome and EEG slowing after a stroke in the basal ganglia is a functional abnormality of the cortex as a consequence of deafferentation from subcortical structures. This hypothesis is consistent with animal studies in which white matter lesions made beneath the cortical surface result in EEG slowing (Luria, 1966) and with findings in humans of reduced glucose metabolism in cortical regions ipsilateral to caudate and internal capsula lacunar lesions (Metter et al., 1981). It is also possible that the absence of ego dystonic components could correlate with a decrease in frontal activity. In fact, Laplane et al. (1989) presented several cases of OCD with low levels of anxiety that resulted from bilateral basal ganglia necrosis, in which there was a decrease in frontal metabolic rate.

First line treatment for OCD includes cognitive behavioural (Dar and Greist, 1992) and/or pharmacological therapy (Jenike, 1992). The specific cognitive behavioural therapy for OCD is exposure and response prevention (Dar and Greist, 1992). The patient was deemed inappropriate for reasons that have been reported to be predictors of treatment failure (Jenike, 1990); these are poor compliance, cognitive impairment, inability to tolerate the demands of the treatment and fixed belief in the necessity of the ritual.

First line pharmacological treatment for OCD are the serotonergic antidepressants, fluoxetine, fluvoxamine, clomipramine, paroxetine and sertraline (Jenike, 1992). An eight week trial of fluoxetine at $40 \mathrm{mg}$ a day following her course of ECT failed to ameliorate her OC symptoms. Guidelines in adults call for increasing fluoxetine doses (Jenike, 1992) in the face of refractory response. However, the patient presented in this paper 
is a geriatric patient, and it was considered that she was already on a relatively high dose because of her age. Therefore, augmentation strategies were applied. The patient began to demonstrate decreased frequency of her OC symptoms after risperidone and lithium were added to her drug therapy. It is unclear which of these two augmenting medications was responsible for the improvement but it is unlikely that the improvement was a consequence of neuroleptic-induced bradykinesia because the patient did not show signs of extrapyramidal symptoms. Despite a decrease in her OC symptoms, the patient continued to manifest profound apathy. Amantadine, an indirect dopaminergic agonist, was added to her therapy because it has been reportedly successful for the treatment of apathy (Marin et al., 1995).

In summary, this report presents, possibly for the first time, a case of OCD that resulted from an unilateral insult to the basal ganglia. In addition, experience in treating a patient with OCD symptoms secondary to known structural damage is presented. Although this patient failed to improve with monotherapy, a satisfactory treatment outcome was achieved with polypharmacy.

\section{REFERENCES}

Baxter LR, Phelps JM, Mazziota JC, Guze BH and Schwartz JM (1987) Local cerebral glucose metabolic rates in obsessive-compulsive disorder: A comparison with rates in unipolar depression and normal controls. Archives of General Psychiatry, 44, 211-218.

Baxter LR, Schwartz JM, Mazziota J, Phelps ME, Pahl JJ, Guze BE and Fairbanks L (1988) Cerebral glucose metabolic rates in nondepressed patients with obsessive-compulsive disorder. American Journal of Psychiatry, 145, 1560-1563.

Croisile B, Tourniare D, Confraveux C, Trillet $\mathrm{M}$ and Aimard G (1989) Bilateral damage to the head of the caudate nuclei. Annals of Neurology, 25, 313-314.

Dar R and Greist JH (1992) Behavior therapy for obsessive compulsive disorder. Psychiatric Clinics of North America, 15, 885-894.

Gloor P, Ball G and Schaul N (1977) Brain lesions that produce delta waves in the EEG. Neurology, 27, 326-333.

Head D, Bolton D and Hymas N (1989) Deficits in cognitive shifting ability in patients with obsessive-compulsive disorder. Biological Psychiatry 25, 929-937.

Insel TR (1992) Toward a neuroanatomy of obsessivecompulsive disorder. Archives of General Psychiatry 49, 739-744.

Jenike MA (1990) Approaches to the patient with treatment-refractory obsessive compulsive disorder. Journal of Clinical Psychiatry 51, 15-21.

Jenike MA (1992) Pharmacologic treatment of obsessive compulsive disorders. Psychiatric Clinics of North America, 15, 895-919.

Khanna S (1988) Obsessive-compulsive disorder: Is there a frontal lobe dysfunction?. Biological Psychiatry, 24, 602-613.

Laplane D, Levasseur M, Pillon B, Dubois B, Baulac M, Mazoyer B, Tran Dinh S, Sette G, Danze F and Baron JC (1989) Obsessive-compulsive and other behavioral changes with bilateral basal ganglia lesions. Brain, 112, 699-725.

Leuchter AF, Cook IA, Lufkin RB, Dunkin J, Newton TF, Cummings JL, Mackey JK and Walter DO (1994) Cordance: a new method for assessment of cerebral perfusion and metabolism using quantitative electroencephalography. Neuroimage, 1, 208-219.

Luria AR (1966) Higher cortical functions in man. Basic Books, New York.

Maraganore DM, Lees AJ and Marsden CD (1991) Complex stereotypes after right putaminal infarction. Movement Disorders, 6, 358-361.

Marin RS, Fogel BS, Hawkins J, Duffy J and Krupp B (1995) Apathy: A treatable syndrome. Journal of Neuropsychiatry and Clinical Neurosciences, 7, 23-30.

Martinot JL, Allilaire JF, Mazoyer BM, Hantouche E, Huret JD, Legaut-Demare F, Deslauriers AG, Hardy P, Pappata S, Baron JC and Syrota A (1990) Obsessivecompulsive disorder: A clinical, neuropsychological and positron emission tomography study. Acta Psychiatrica Scandinavica, 82, 233-242.

Metter EJ, Wasterlain CG, Kuhl DE, Hanson WR and Phelps ME (1981) 18FDG positron emission tomography in a study of aphasia. Annals of Neurology, 10, 173-183.

Nordahl TE, Benkelfat C, Semple W, Gross M, King AC and Cohen RM. (1989) Cerebral glucose metabolic rate in obsessive-compulsive disorder. Neuropsychopharmacology, 2, 23-28.

Rubin RT, Villanueva-Meyer J, Ananth J, Trajmar PJ and Mena I (1992) Regional xenon 133 cerebral blood flow and cerebral technetium Tc 99m-HMPAO uptake in unmedicated patients with obsessive-compulsive disorder and matched normal control subjects: Determination by high resolution single-photon emission computed tomography. Archives of General Psychiatry, 49, 695-702.

Swedo SE, Schapiro MB, Grady CL, Cheslow DL, Leonard HL, Kumar A, Friedland R, Rapoport SI and Rapoport JL (1989) Cerebral glucose metabolism in childhoodonset obsessive-compulsive disorder. Archives of General. Psychiatry, 46, 518-523.

Weilburg JB, Mesulam M-M, Weintraub S, Buonanno F, Jenike M and Stakes JW (1989) Focal striatal abnormalities in a patient with obsessive-compulsive disorder. Archives of Neurology, 46, 233-235.

(Received 21 March 1997; accepted as revised 25 May 1997) 


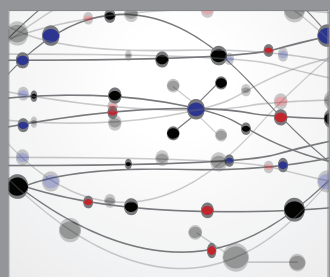

The Scientific World Journal
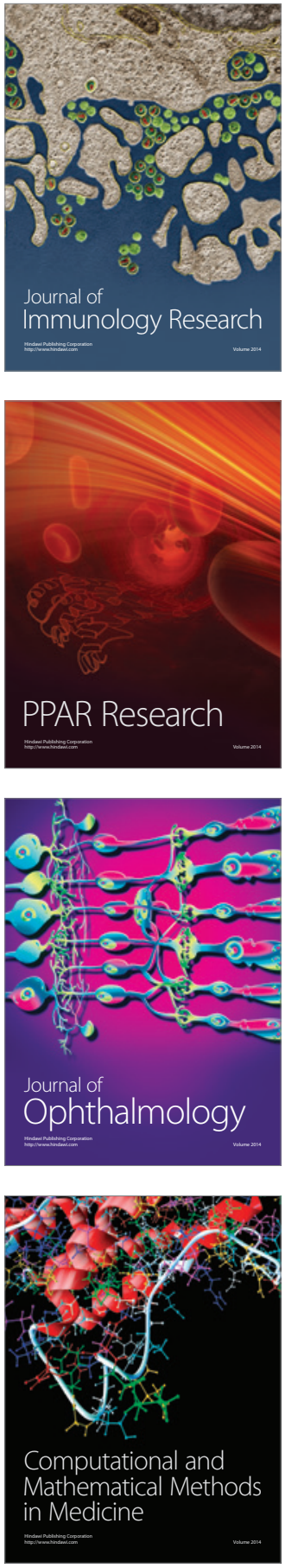

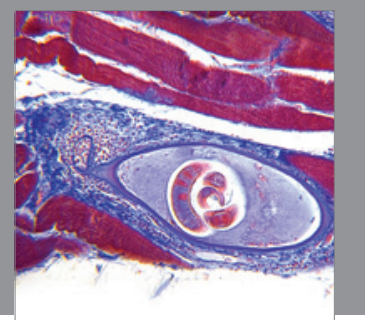

Gastroenterology

Research and Practice
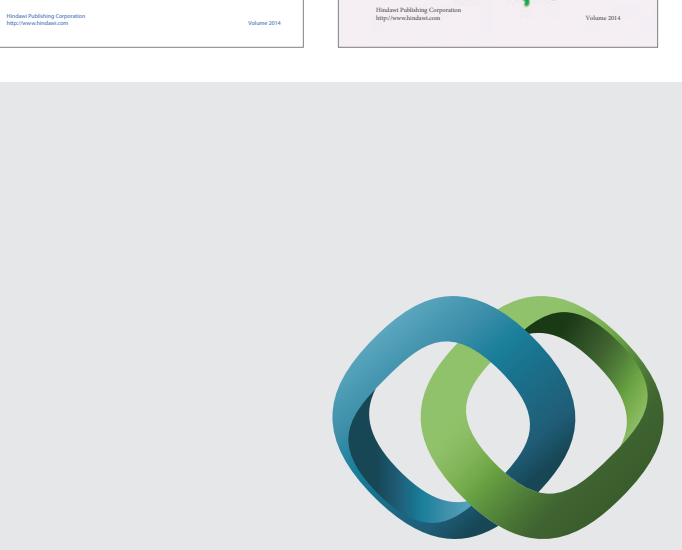

\section{Hindawi}

Submit your manuscripts at

http://www.hindawi.com
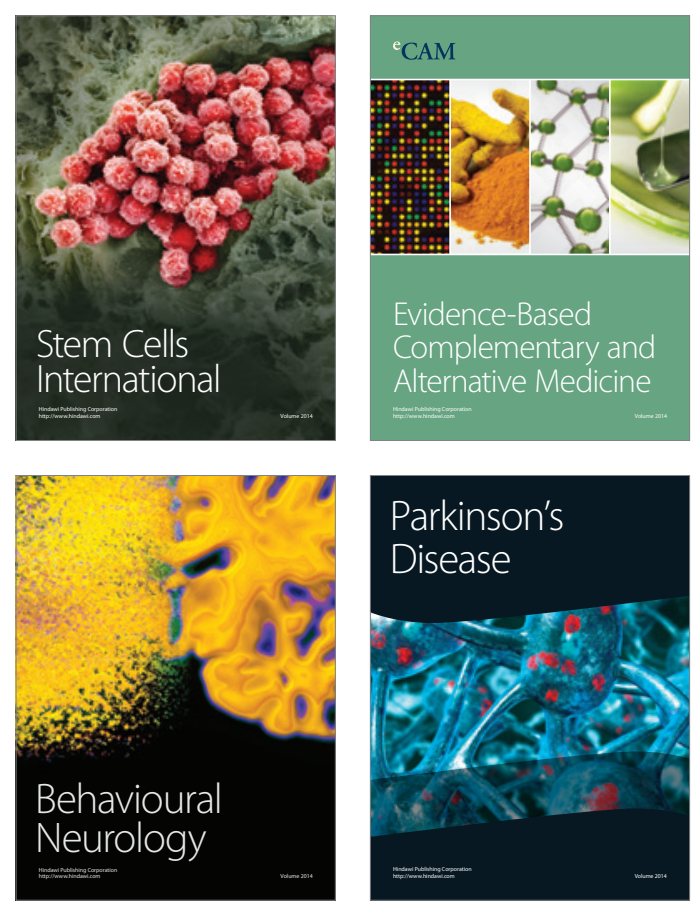

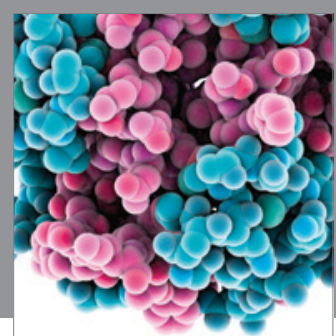

Journal of
Diabetes Research

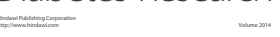

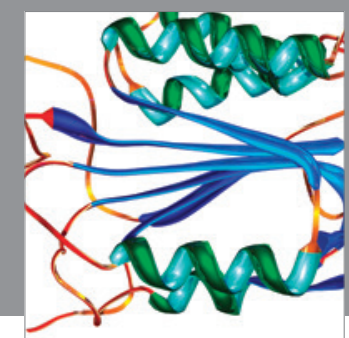

Disease Markers
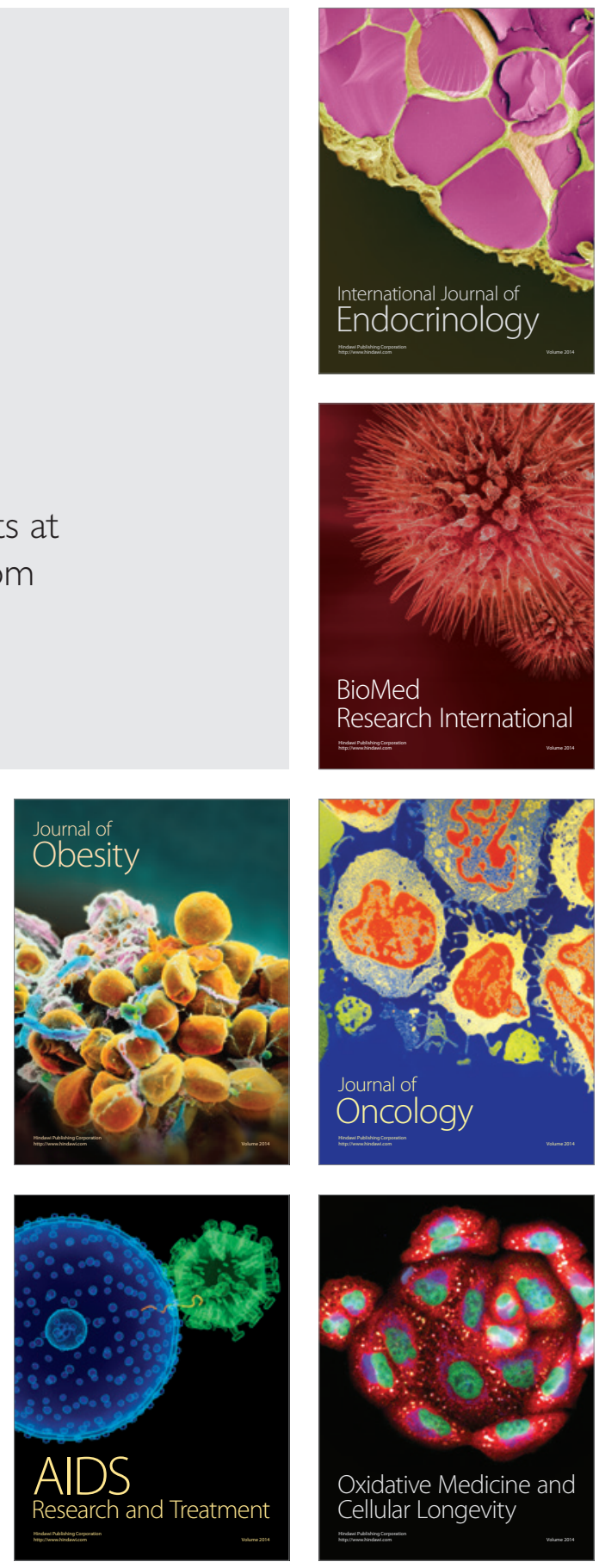